\title{
Separate Control of the Survival, the Self-renewal and the Differentiation of Hemopoietic Stem Cells
}

\author{
Takanori Yanai ${ }^{1, \dagger}$, Kenkichi Sugimoto ${ }^{1}$, Emi Takashita $^{1}$, Yohko Aihara ${ }^{1}$, Youko Tsurumaki ${ }^{1}$, \\ Takashi Tsuji ${ }^{1,2}$, and Kazuhiro J. Mori ${ }^{1}$ \\ ${ }^{1}$ Department of Biology, Faculty of Science, Niigata University, Niigata 950-21, and ${ }^{2}$ Life Science Research \\ Laboratory, Japan Tobacco Inc., Yokohama, Kanagawa 227, Japan
}

Key words: hemopoietic stem cell/extracellular matrix/stem cell factor/hemopoietic supportive stroma/serum-free medium

\begin{abstract}
Hemopoietic stem cells adhere to hemopoietic supportive (MS-5) cells, but not to non-supportive (MS-K) cells. Although a soluble stem cell factor (SCF) was produced by both of these cell lines, little activity was detectable in the supernatant from the cultures of either of these cells, indicating that SCF might be compartmentalized within the extracellular matrix (ECM), and transferred directly to the stem cells via the ECM (44).

To probe this possibility, we studied the transfer of SCF from the ECM and the subsequent support of the survival of the hemopoietic stem cells. A stem cell-enriched bone marrow cell fraction was overlaid on SCF-containing ECM. The stem cells survived and proliferated for some days without differentiation under these conditions, whereas stem cells overlaid on ECM without SCF died within a few days. Addition of interleukin-3 (IL-3) to the ECM that contains SCF, induced differentiation of the stem cells. Granulocyte-macrophage colony-stimulating factor (GM-CSF) induced further differentiation of the stem cells, which was accompanied by a decrease in the number of colony-forming unit in spleen (CFU-S).

These observations verified the above hypothesis, and indicated that the survival, the self-renewal, and the differentiation of hemopoietic stem cells can be separately controlled at least in vitro.
\end{abstract}

The importance of bone marrow stroma in the regulation of hemopoiesis is well known. The stromal cells support the proliferation and differentiation of hemopoietic stem cells by direct intercellular interactions (7, $28)$, as well as by the cytokines they produce $(24,44$, 48).

Proliferation and differentiation of stem cells appear to depend on the contact of the stem cells with hemopoietic supportive stromal cells. Stem cells 'trapped' underneath the stromal cells in bone marrow cell culture are protected from the effect of the exogenous stimulus of growth factor (23). Thus, one of the major functions of the hemopoietic supportive stromal cells resides in the propensity of stem cells to adhere to them $(6,28,44)$. SCF (1) produced by the stromal cells appears to be concentrated within the ECM of the stromal cells, as reported by Gordon et al. for colony-stimulating factor

\footnotetext{
Abbreviations: SCF, stem cell factor; IL-3, interleukin-3; GMCSF, granulocyte-macrophage colony-stimulating factor; ECM, extracellular matrix; EHS-CEX, Englebreth-Holm-Swarm cell-extract; i.v., intravenous injection; HPM, hemopoietic 'permissive' microenvironment; HSM, hemopoietic 'supportive' and 'selective' micro-environment.

$\dagger$ To whom correspondence should be addressed.
}

(CSF) (11), and is transferred directly to the stem cells, since both the supportive (MS-5) $(2,17,44)$ and nonsupportive (MS-K) (41) stromal cells produce SCF of the soluble type, and yet the latter cells, to which the stem cells do not adhere, cannot support the proliferation and differentiation of the stem cells (44).

The control mechanism of the self-renewal and differentiation of hemopoietic stem cells has been the subject of debate. Trentin reported that the differentiation of hemopoietic stem cells into the erythroid or granulocyte lineage was controlled by the hemopoietic inductive microenvironment (HIM) (47). Johnson and Metcalf claimed that the differentiation of hemopoietic stem cells to erythroid and granulocyte lineages was stochastic (18). Ogawa et al. also presented a stochastic model of hemopoietic stem cell-differentiation based on their data obtained from clonal cultures of hemopoietic progenitor cells (32). In contrast, Frindel et al. found that hemopoietin induced the commitment of CFU-S to the erythroid lineage (9).

Aim of the present study was, firstly, to provide evidence to back the hypothesis that SCF, concentrated within ECM of the stromal cells, is transferred to hemopoietic stem cells that adhere to the stromal cells and 
supports the survival and proliferation of the stem cells.

IL-3 (14) and a high concentration of GM-CSF (22) are known to stimulate the proliferation and differentiation of stem cells. Accordingly, the effects of ECM containing IL-3 on stem cell behavior was also studied, although the stromal cells did not produce any IL-3 activity.

In the second part of the present study, we investigated the effects of SCF, IL-3, and GM-CSF concentrated within ECM layer on the kinetics of hemopoietic stem cells, to clarify whether or not the survival, the self-renewal, and the commitment to differentiation of the stem cells can be controlled independently.

We found that SCF-containing ECM supported the survival and stimulated the proliferation of stem cells. We also found that the survival, the self-renewal and the differentiation of hemopoietic stem cells could be controlled separately when these growth factors were transferred directly to stem cells via cell contact in a protein-free culture system. Addition of horse serum to this system changed the response completely, and showed that the use of serum, which certainly contain a number of growth factors, modifies the response of hemopoietic stem cells to growth factors, resulting in an apparently stochastic response.

\section{MATERIALS AND METHODS}

Mice. Male mice of $\mathrm{C} 3 \mathrm{H} / \mathrm{HeN}$ strain were purchased from Sankyo Laboratory (Japan), and kept under specific pathogen-free conditions. They were used at the ages of 10-14 weeks.

Medium. Since serum-free medium contains bio-extracts such as BSA, transferrin and pituitary extract as substitutes for serum and may affect the response of the stem cells to ECM, protein-free alpha-MEM was applied in all the experiments.

Growth factors and ECM. SCF, IL-3 and GM-CSF were chosen as the growth factors which act on hemopoietic stem cells. Recombinant (r) mouse SCF (soluble type), r-IL-3 (mouse), and r-GM-CSF (mouse) were kindly provided by Kirin Beer Co. Ltd. Englebreth-Holm-Swarm (EHS) cell extract $(\mathrm{CEX})(19,34,36)$ was purchased from Iwaki Glass Co. (Japan). EHS-CEX was extracted by urea from EHS tumor and reconstituted under physiological conditions on the surface of culture dishes. This material has potent effects on the morphology and the function of cells, and can be cultured either within or on the gel. In general, cells cultured under these conditions exhibit a similar expression as that seen in vivo (20). Porcine type I collagen (Cellmatrix Type-IA), and bovine type IV collagen (Cellmatrix Type-IV) were provided by Nitta Gelatin Co. (Japan). Bovine serum albumin (BSA) (crystallized) was purchased from Sigma (U.S.A.).

Release of growth factors from ECM to culture medium. SCF $(100 \mathrm{ng} / \mathrm{ml})$, GM-CSF $(100 \mathrm{U} / \mathrm{ml})$ or IL-3 $(500 \mathrm{U} / \mathrm{ml})$ were mixed in ECM layers (EHS-CEX, $8.6 \mathrm{mg} / 2 \mathrm{ml} /$ dish; collagen I+IV, $4.8 \mathrm{mg} / 2 \mathrm{ml} /$ dish) and $3 \mathrm{ml}$ of each protein-free alpha-MEM were added, and incubated for $24 \mathrm{hr}$ at $4^{\circ} \mathrm{C}$. After the incubation, the medium was collected and each activity was assayed. SCF activity was assayed by mast cell colony assay $(4,38)$, GM-CSF activity was assayed by CFU-GM assay (4) and IL-3 activity was assayed by DA-1 assay $(13,15)$.

Coating of Petri dishes with individual components of ECM with or without growth factors. EHS-CEX was dissolved in the protein-free alpha-MEM at a concentration of $4.3 \mathrm{mg} / \mathrm{ml}$, equivalent volumes of neutralized collagen type I and IV were dissolved in the protein-free alpha-MEM at a concentration of $2.4 \mathrm{mg} / \mathrm{ml}$, and $3 \mathrm{ml}$ of each was spread on the bottom of Petri dishes (diameter: $60 \mathrm{~mm}$ ) to form a thin layer. SCF, IL-3, and GM-CSF were dissolved at a final concentration of $20 \mathrm{ng} / \mathrm{ml}, 20$ and $100 \mathrm{units} / \mathrm{ml}$, respectively, in each of ECM components immediately before coating the dishes.

EHS-CEX and collagen were used as a model of cellular ECM.

Enrichment of stem cells from bone marrow cells. Percoll (Pharmacia, U.S.A.) solution was used to fractionate the bone marrow cells, as described previously $(24,43)$. The $\mathrm{pH}$ and osmolarity of the gradient was 7.0 and $300 \mathrm{mosM} / \mathrm{Kg}$, respectively. After centrifugation at $1,500 \times \mathrm{g}$ for $30 \mathrm{~min}$ at $20^{\circ} \mathrm{C}$, a cell fraction of $1.060<\rho<1.074$ was passed through a G10 column to remove adherent cells, and elutant containing non-adherent cells was collected as the stem cell-enriched population. The fraction contained more than 20 fold-concentrated CFU-S.

Incubation. The cell adhesion assay (40) was performed as follows unless otherwise described. Petri dishes (diameter: $60 \mathrm{~mm}$ ) were coated with ECM proteins (concentration: EHSCEX, $0.43 \mathrm{mg} / \mathrm{ml}$; collagen I+IV, $0.3 \mathrm{mg} / \mathrm{ml}$ ) in $3 \mathrm{ml}$ phosphate buffered saline $(145 \mathrm{mM} \mathrm{NaCl}, 10 \mathrm{mM}$ phosphate buffer, $\mathrm{pH}$ 7.2; PBS) overnight at $4^{\circ} \mathrm{C}$. The remaining protein absorption sites in each dish were then saturated with $10 \mathrm{mg}$ $/ \mathrm{ml}$ heat-denatured BSA $\left(80^{\circ} \mathrm{C}\right.$ for $\left.3 \mathrm{~min}\right)$ in PBS for $30 \mathrm{~min}$ at $25^{\circ} \mathrm{C}$. After washing with PBS 3 times, dishes were used for cell adhesion. The stem cell-enriched populations of mouse bone marrow cells were overlaid on top of a layer of each component of ECM $\left(1 \times 10^{6}\right.$ cells $/ 6 \mathrm{ml} /$ dish $)$. After $2 \mathrm{hr}$, cells in the suspension were decanted and removed by gently shaking the dishes and washing them with alpha-MEM 3 times. Adherent cells were collected by scraping the layer with a rubber policeman, and a single cell suspension was obtained by pipetting.

For assaying the supportive activity of the ECM and growth factors, the stem cell-enriched population $\left(1 \times 10^{6}\right.$ cells $/ 3 \mathrm{ml}$ /dish) was overlaid on the layer of ECM with or without growth factor(s), and incubated for 8 days. Incubation was not prolonged further to avoid any undesirable effects of the metabolites of the cells that may act in a similar way as serum.

Assay of CFU-S and CFU-GM. Cells in the Petri dishes were collected at 2, 4, 5 and 8 days after the start of the incuba- 
tion by washing the dishes with growth medium. The number of CFU-S in each dish was determined according to the technique of Till and McCulloch (46). The appropriate number of test cells were injected i.v. into lethally irradiated mice, and spleen colonies were counted on day 8 and day 12 .

The number of CFU-GM was determined by a modified technique of Bradley and Metcalf (4). The cells for assay were cultured in 35-mm plastic Petri dishes $\left(5 \times 10^{4}\right.$ cells $\left./ 2 \mathrm{ml}\right)$ in alpha-MEM containing 20\% horse serum, 5\% mouse abdominal wall-conditioned medium as CSF, and $0.3 \%$ (w/v) bacto agar (Difco, U.S.A.). The culture was maintained at $37^{\circ} \mathrm{C}$, $5 \% \mathrm{CO}_{2}$ in humidified air for 7 days, and clusters consisting of 50 or more cells were counted as colonies.

\section{RESULTS}

Release of factors into supernatant from ECM layer. To determine the specific binding of the factors to the ECM, the factors that were mixed with the ECM layer consisted of collagen I+ IV or EHS-CEX, and the release into the supernatant of the factors that were bound to the ECM layer was examined. The majority of IL-3 and GM-CSF was released into the supernatant from the ECM layer (Fig. 1) when IL-3 and GM-CSF were mixed in the ECM layer. But there still remained concentrated amounts of IL-3 and GM-CSF within the ECM as reported by Gordon et al. (11). In contrast, SCF was not released from ECM layer (Fig. 1).

Adhesion of $C F U-S$ to ECM layer. Adhesion of the stem cell-enriched fraction to dishes coated with ECM layer was studied. Cells attached to each of the ECM layers were used for the assay of CFU-S (Fig. 2) and CFU-GM (data not shown). A several-fold increase in

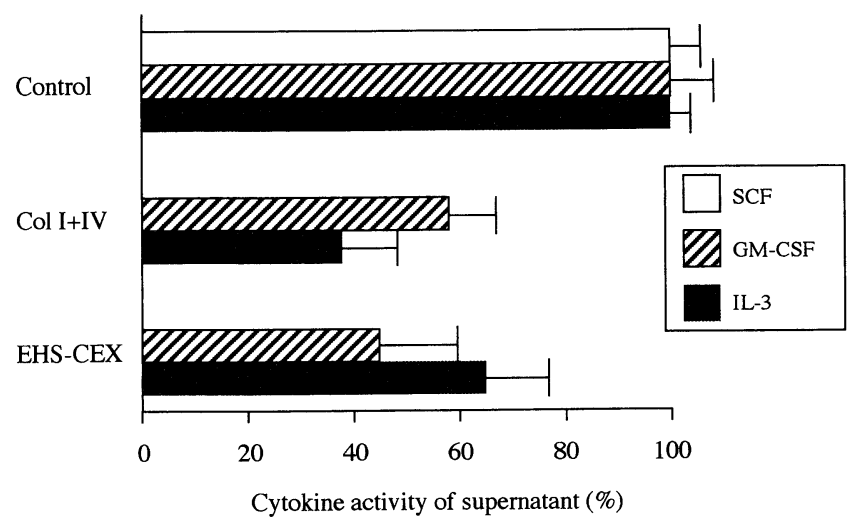

Fig. 1. Release of SCF, GM-CSF and IL-3 activity from ECM to culture medium. SCF $(100 \mathrm{ng} / \mathrm{ml})$, GM-CSF $(100 \mathrm{U} / \mathrm{ml})$ or IL-3 (500 $\mathrm{U} / \mathrm{ml}$ ) were mixed in ECM layers $(2 \mathrm{ml}$ per dish), and $3 \mathrm{ml}$ each protein-free alpha-MEM were added, and incubated for $24 \mathrm{hr}$ at $4^{\circ} \mathrm{C}$. After the incubation, the medium was collected and SCF, GM-CSF and IL-3 activity were assayed.

Results: means \pm S.E. $(n=3)$

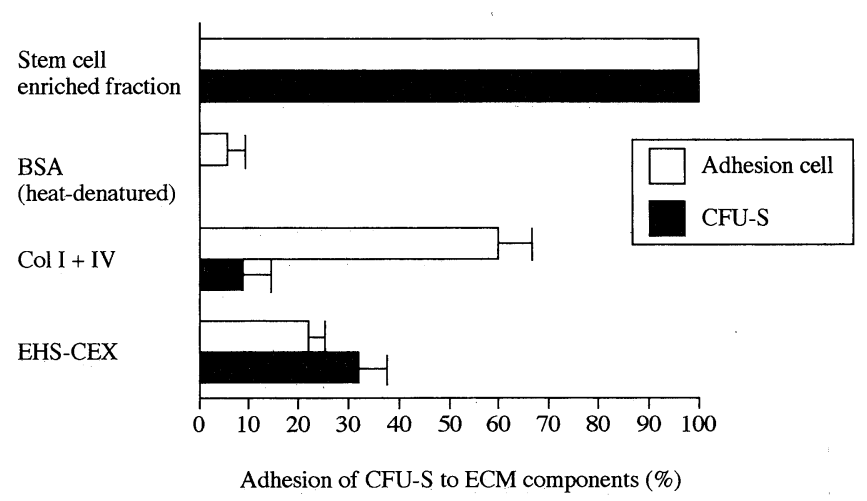

Fig. 2. The stem cell enriched fraction $\left(380 \pm 27 \mathrm{CFU}-\mathrm{S} / 1 \times 10^{6}\right.$ cells per dish) was seeded onto Petri dish coated with each of ECM components. The cells were incubated at $37^{\circ} \mathrm{C}$ for 2 hours. After the incubation, adherent cells were havested, and evaluated. Adherent cells were used for CFU-S assay.

$\square$; Ratio of adherent cells: (No. of adherent cells/No. of seed cells) $\times$ 100, $\square$; Ratio of CFU-S: (No. of CFU-S/No. of CFU-S of seed cells) $\times 100$

Results: means \pm S.E. $(n=10)$

the number of CFU-S and CFU-GM was observed.

Kinetics of $C F U$-S seeded onto SCF-containing ECM layer. Kinetics of the cells in the stem cell-enriched fraction seeded onto SCF-containing ECM was studied. The effect of SCF on viable cell numbers of CFU-GM and CFU-S, in the protein-free liquid culture of the stem cell-enriched fraction was also examined.

In the absence of SCF, no viable cells were recovered after 2 days of incubation (Fig. 3). In contrast, a significant number of day-12 (Fig. 4) and day-8 (Fig. 5) CFU$\mathrm{S}$ were recovered in the culture with SCF. SCF also supported the survival of CFU-GM (Fig. 6).

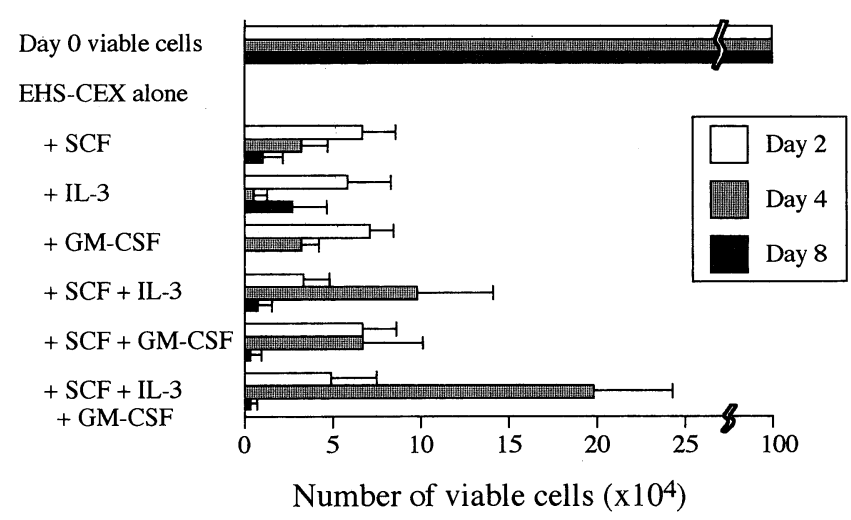

Fig. 3. Effect of growth factors on the number of viable cells. The stem cells enriched fraction $\left(1 \times 10^{6}\right.$ cells per dish) was overlaid onto ECM derived from EHS-sarcoma. The cells were harvested after 2,4 , or 8 days, and viable cells were evaluated by trypan blue staining. $\square ; 2$ days after the start of the culture, 㥼; 4 days after the start of the culture, $\square ; 8$ days after the start of the culture.

Results: means \pm S.E. $(n=10)$ 


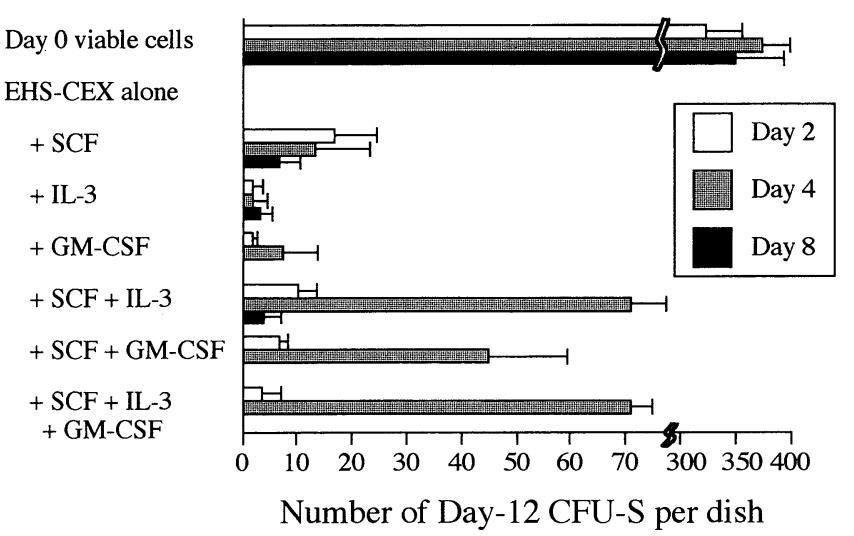

Fig. 4. Effect of growth factors on the number of Day-12 CFU-S. The stem cells enriched fraction $\left(1 \times 10^{6}\right.$ cells per dish) was overlaid onto ECM from EHS-sarcoma. The cells were harvested after 2, 4, or 8 days. Harvested cells were injected into lethally irradiated mice and spleen colonies were counted at day 12 .

$\square ; 2$ days after the start of the culture, 躧; 4 days after the start of the culture, $\square$; 8 days after the start of the culture.

Results: means \pm S.E. $(n=10)$

The kinetics of the stem cell-enriched fraction seeded onto SCF-containing collagen gel was compared to that with EHS-CEX used as total cellular ECM. Collagen gel supported significantly fewer CFU-GM and CFU-S at day 8, and the number of CFU-GM and CFU-S rapidly declined thereafter (data not shown).

Induction of differentiation of CFU-S by IL-3-containing ECM. Effects of SCF and IL-3 on self-renewal and differentiation of CFU-S were elucidated. Culture of stem cell-enriched fraction of bone marrow cells on

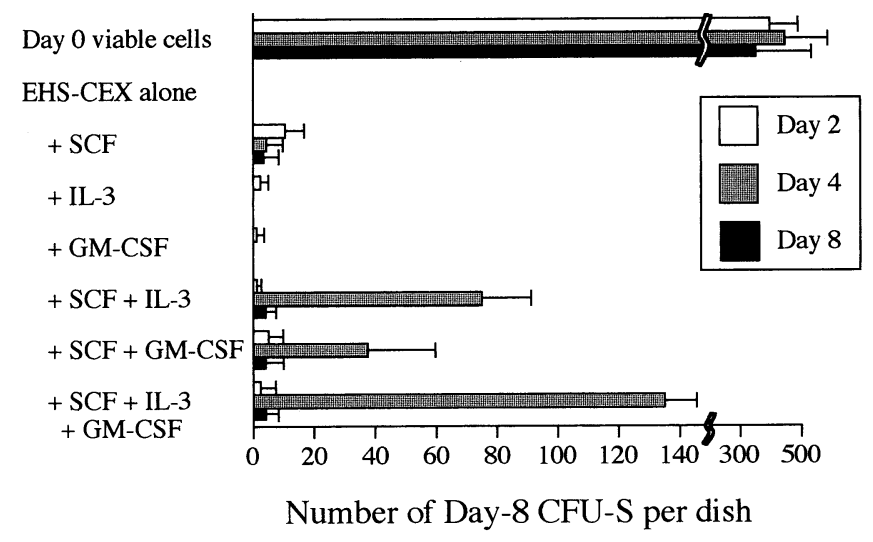

Fig. 5. Effect of growth factors on the number of Day-8 CFU-S. The stem cells enriched fraction $\left(1 \times 10^{6}\right.$ cells per dish) was overlaid onto the layer of EHS-derived ECM. The cells were harvested after 2, 4 , or 8 days, and were injected into lethally irradiated mice. Spleen colonies were counted at day 8 after the injection.

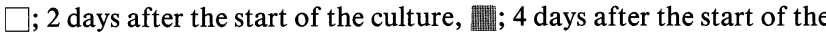
culture, $\square ; 8$ days after the start of the culture.

Results: means \pm S.E. $(n=10)$

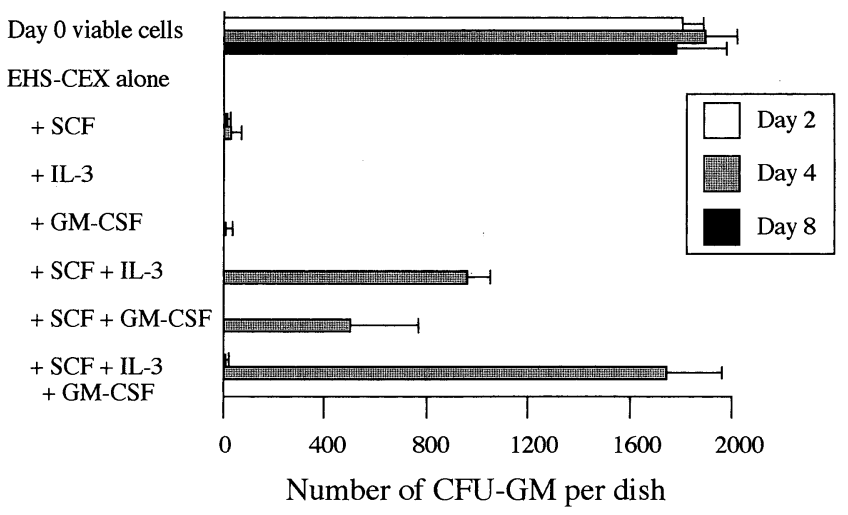

Fig. 6. Effect of growth factors on the number of CFU-GM.

The stem cells enriched fraction $\left(1 \times 10^{6}\right.$ cells per dish) was overlaid onto ECM from EHS-sarcoma. The cells were harvested after 2, 4, or 8 days. Harvested cells were incubated in alpha-MEM containing $20 \%(\mathrm{v} / \mathrm{v})$ horse serum and 5\% (v/v) AWCM (mouse abdominalwall-conditioned medium) as CSF, and $0.3 \%$ Bact agar. Clusters consisting of 50 or more cells were counted as colonies.

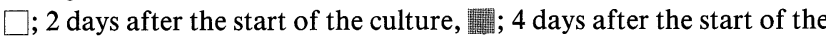
culture, $\square$; 8 days after the start of the culture.

Results: means \pm S.E. $(n=10)$

ECM containing SCF and IL-3, resulted in a significantly greater number of CFU-GM and day-8 CFU-S than on ECM containing SCF alone after 4 days in culture (Figs. 4-6). Moreover, CFU-GM increased from 2 days to 4 days (Fig. 6). Viable cells were scarcely detectable at 8 days in culture, which may be due to the poor culture conditions (Fig. 3).

Effects of GM-CSF-containing ECM on stem cell kinetics. The combination of SCF, IL-3 and GM-CSF not only maintained viable cell numbers but also induced an increase in the number of CFU-GM and day-8 CFU-S. In fact, they increased in number from at 2 days to 4 days (Figs. 3-6). There was no increase in the number of CFU-S in the culture containing GM-CSF alone. At day 4, the numbers of viable cells, CFU-GM and day-8 CFU-S supported by SCF + IL-3 + GM-CSF, were approximately twice as many as those supported by SCF + IL-3. On the other hand, the number of day12 CFU-S decreased significantly. Viable cells, CFUGM and CFU-S, were undetectable after 8 days of culture.

Modification of stem cell kinetics by horse serum. Effects of the presence of horse serum on the kinetics of the stem cells were studied in the present culture system. Horse serum was chosen because it supports the in vitro maintenance of murine bone marrow culture $(7,28)$.

Horse serum alone did not support the survival of the stem cells in the suspension culture, as previously reported (6). Addition of horse serum to the culture of bone marrow cells on collagen, modulated the kinetics of the stem cells. Addition of horse serum resulted in 
the deterioration of the culture rather than further enhancement of the survival of the stem cells. The effects of SCF and IL-3 were also modified by the serum. The self-renewal of the stem cells induced by SCF was abrogated, and the induction by IL-3 of differentiation of the stem cells into CFU-GM also was cancelled by the serum (data not shown).

\section{DISCUSSION}

Attachment of stem cells to hemopoietic supportive stromal cells appears to be an essential first step in the survival of the stem cells $(2,7,29,44)$. SCF seems to be transferred directly from the stromal cells to the stem cells through the ECM (44), supporting explaining again the local control mechanism of hemopoiesis. IL-3 is known to stimulate the proliferation of stem cells which are already in cycle and express IL-3 receptors (14). SCF-deficient mice have a normal number of CFU-S and transplantable stem cells (21), suggesting that survival and proliferation of primitive progenitors may not be dependent on SCF. However, survival and proliferation of primitive progenitors is supported by direct contact with MS-5 $(2,17,44)$, and the proliferation of primitive human $\mathrm{CD} 34^{+} / \mathrm{CD} 38^{-}$progenitor cells is also supported by direct contact with MS-5 (16).

Major differences between the characteristics of hemopoietic supportive (MS-5) cells and non-supportive (MS-K) cells are that MS-5 cells are adhered to by a large number of stem cells, and begin to produce GMCSF, whereas MS-K cells are scarcely adhered to by stem cells, and do not produce GM-CSF $(24,44)$. Both cell lines produce and secrete substantial levels of IL-6 and M-CSF, indicating that these growth factors alone are not responsible for the hemopoietic supportive function of MS-5 cells. Neither of the cell lines produces IL3.

Although both MS-5 and MS-K produce SCF, the level of SCF activity in the culture supernatant was significantly low compared to the level of expression of mRNA for SCF. Furthermore, the supernatant of these cell cultures did not support the survival of the stem cells. The MS-K cells, to which stem cells do not adhere, did not support the survival, proliferation, or differentiation of the stem cells (41), although MS-K cells produce SCF (44). Roberts et al. have reported that growth-factor-dependent multipotent cells survive and proliferate, when these cells are overlaid on ECM which had been pre-incubated with IL-3 or GM-CSF (37). Accordingly, we postulated that SCF produced by MS-5 and MS-K cells was compartmentalized within ECM, and transferred directly to hemopoietic stem cells via cell adhesion (44). The hemopoietic supportive mechanism of MS-5 can be summarized as follows: Firstly, MS- 5 adheres stem cells by specific adhesion molecules as well as by ECM, and secondly, SCF, which is transferred directly to stem cells via cell adhesion, supports the survival and proliferation of the stem cells.

Regulation of hemopoiesis appears to be locally controlled. Recovery of hemopoietic stem cells after irradiation or drug-treatment is significantly faster in the spleen than in the bone marrow $(10,31,39)$. When stem cells are already in the resting state in the spleen of phenylhydrazine-treated mouse, they are still in full cycle in the bone marrow (35). Miyanomae et al. showed that stem cells 'trapped' underneath the stromal cell layer were protected from the effect of added GM-CSF (23), explaining one of the local control mechanisms of hemopoiesis.

Another possibility is that growth factors produced by the stromal cells act only at a short distance. Suzuki et al. found that SCF produced by bone marrow stromal cells is not released into the culture medium but compartmentalized within the ECM (44) and transferred directly to stem cells via cell adherence. This would support in part this second possibility.

Whether the proliferation and differentiation of hemopoietic stem cells is stochastic or inductive has been a matter of debate. In normal mice, only $40 \%$ of the stem cells that proliferate take the pathway of differentiation, but when the stem cell compartment decreases to less than $10 \%$ of its normal level, only self-renewal of the stem cells occurs (5), indicating that self-renewal and commitment to the differentiation pathway are controllable. We have also shown that irradiated hemopoietic supportive stromal cells in vitro induce an increased in self-renewal rather than stochastic proliferation and differentiation $(25,30)$.

All the studies on hemopoietic regulatory mechanisms so far have been carried out either in vivo or in vitro in the presence of serum or bio-extracts such as bovine serum albumin (BSA), transferrin and pituitary extract even when so-called serum-free medium was used. We have previously reported that the addition of horse serum or BSA modulates the activity of IL-3 in terms of its GM-CSF activity (42). By using a particular batch of fetal calf serum (FCS), we showed that IL-3 had no GM-CSF activity, but such activity could be induced by a co-factor that exists in BSA, horse serum and calf serum. Thus, even the use of serum-free culture medium could affect the actual mechanism(s) underlying the control of stem cell kinetics. Accordingly, we have used a protein-free culture system in the present experiments to avoid the undesirable effects of serum or bio-extracts such as BSA.

The present study has revealed that the stem cell-enriched population of bone marrow cells adhered to collagen and EHS-CEX, indicating that these ECM participate in the stem cell adherence to stromal cells.

In the second set of experiments, the effects of ECM 
and growth factors on the kinetics of hemopoietic stem cells were studied. Protein-free culture, as well as cultures containing horse serum, did not support the survival of the stem cells in the suspension culture for more than four days. Thus, the necessity of the hemopoietic supportive stromal cells, as previously reported $(2,7$, $29,44)$, was confirmed. However, the addition of collagen type I, IV, laminin or heparansulfate to the suspension cultures allowed the stem cells to survive, but there was no changes in their number from day 4 to day 8 of culture (Sugimoto et al., to be published). The finding clearly indicates that the survival of the stem cells is supported by certain components of ECM of the stromal cells to which the hemopoietic stem cells adhere.

Since the hemopoietic stem cells $(2,44)$ adhere to MS5 cells (17), and induce MS-5 to produce GM-CSF (45), the effect of SCF concentrated within EHS cell-derived ECM was investigated. The stem cells proliferated on the SCF-containing ECM and their numbers increased without accompanying increase in the number of CFUGM. Addition of IL-3 enhanced the proliferation and also induced the differentiation of the stem cells. Subsequent addition of GM-CSF to this culture further induced the differentiation of the stem cells to CFU-GM. In this case, the number of the stem cells decreased in parallel with the increase in the number of their progeny.

These observations demonstrate convincingly that the survival, the self-renewal, and the differentiation of hemopoietic stem cells are separately controllable in culture. The present study confirms the inductive theory of the stem-cell differentiation of Trentin (47) at least in vitro. The commitment of the stem cells to differentiation was also shown to be controlled separately from proliferation.

Coulombel's group reported recently that the proliferation of primitive human $\mathrm{CD} 34^{+} / \mathrm{CD} 38^{-}$progenitor cells is supported by direct contact with hemopoietic supportive stromal cells (MS-5) of murine origin (16). Moreover, the proliferation of the hemopoietic progenitor cells was not accompanied by an increase in the differentiated cells. We have also found that proliferating $\mathrm{CD} 34^{+} / \mathrm{CD} 38^{-} / \mathrm{DR}^{-}$human hemopoietic cells could be maintained without differentiation for more than 12 weeks (to be published).

These observations support the above concept, that the survival and proliferation of the stem cells is separately controlled from commitment to differentiation, although the unusual combination of murine stromal cells and human hemopoietic cells should be taken into account.

Taking these observations together with the present findings, we propose the following control mechanism of the stem cell kinetics. 1) The survival of the stem cells is supported by the ECM of and yet unknown factors produced by stromal cells; 2) the self-renewal of the stem cells is stimulated by SCF via a direct transfer of the factor from the hemopoietic supportive stromal cells to the stem cells, and 3 ) the differentiation of the stem cells is induced by IL-3 and GM-CSF.

The limitations of in vitro observations have to be considered before we are able to claim that these observations represent the in vivo phenomenon (27), since the separate control of the survival, the self-renewal, and the differentiation of the stem cells in the proteinfree culture system may not be applicable directly to the in vivo situation. In fact, some ECM components such as collagen affected the behavior of the hemopoietic cells induced by SCF. Serum is required for CSF-induced proliferation of the factor-dependent macrophage cell lines (33). The requirements of serum factors present in FCS have been reported for the proliferation of macrophages $(8,49)$ and a factor-dependent hemopoietic cell line (3). We have previously shown that even the use of BSA modifies the activity of IL-3 qualitatively (42). Moreover, the long-term culture of murine bone marrow cells requires horse serum $(7,29)$; the addition of FCS (12), and the use of mouse serum (Mori K.J., unpublished observation) deteriorate the culture system. A variety of growth factors, stromal cells, and other accessory cells may modify the kinetics of the stem cells in conventional cultures and in vivo. In fact, the activity of IL-3 is modified by a co-factor, which exists in BSA (42), calf serum and horse serum $(22,42)$. Thus, conventional culture with serum, or serum-free culture using a medium that contains bio-extracts, may not reveal the inherent response of the stem cells to growth factors or to ECM, due to the effects of other growth factors and unidentified activities that exist in these bio-extracts. We found again in the present study that addition of horse serum to the protein-free culture system markedly modified the response of the stem cells to ECM, SCF, IL-3 and GM-CSF.

Thus, the scheme we propose herein does not necessarily exclude the concept that the proliferation and differentiation of hemopoietic stem cells is stochastic in certain situations. Expression of the receptors for SCF and lineage specific differentiation-inducing growth factors on the stem cells and progenitors is supposedly stochastic. However, the growth factors necessary for the survival and differentiation of the stem cells may be restricted quantitatively. The survival and proliferation of the stem cells is then permitted only in the presence of ECM and/or SCF, and the differentiation of the cells to certain cell lineages is supported selectively by the differentiation-inducing growth factors, such as G-CSF produced by the stromal cells and other accessory cells in the hemopoietic tissues. The results would than appear to be 'inductive' as Trentin has reported (47).

The present observations support the concept of he- 
mopoietic 'permissive' microenvironment (HPM) or hemopoietic 'supportive' and 'selective' micro-environment (HSM) proposed by Mori (26).

Acknowledgements. We would like to acknowledge the continuing advice of Dr. Tohru Inoue (Yokohama City University). This work was supported by Grants-in-Aid for Science Research (A) from The Ministry of Education, Science and Culture, Kato Memorial Bioscience Foundation, and Saneyoshi Scholarship Foundation, Japan. We also wish to express our thanks to Kirin Beer Co., Sankyo Co. and Wakenyaku Co. for their financial support.

\section{REFERENCES}

1. Aizawa, S., Hojo, H., Tsuda, A., Sai, M., and Toyama K. 1991. Rosette formation between stromal and hemopoietic cells: A simple assay for the supportive activity of stromal cell Leukemia, 5: 273-276.

2. Anderson, D.M., Lyman, S.D., Baird, A., Wignall, J.M., Eisenman, J., Rauch, C., March, C.J., Boswell, H.S., Gimpel, S.D., Cosman, D., and Williams, D.E. 1990. Molecular cloning of mast cell growth factor, a hematopoietin that is active in both membrane bound and soluble forms. Cell, 63: 235243.

3. BoHMER, R.M. 1989. Interaction of serum and colony-stimulating factor for survival of a factor-dependent hemopoietic progenitor cell line. J. Cell. Physiol., 139: 531-537.

4. Bradley, T.R. and Metcalf, D. 1966. The growth of mouse bone marrow cells in vitro. Aust. J. Exp. Biol. Med. Sci., 44: 287-299.

5. Chervenick, P.A. and Boggs, D.R. 1971. Patterns of proliferation and differentiation of hematopoietic stem cells after compartment depletion. Blood, 37: 568-580.

6. Dexter, T.M., Allen, T.D., and Lajtha, L.G. 1977. Conditions controlling proliferation of hemopoietic stem cells in vitro. J. Cell. Physiol., 91: 335-344.

7. Dexter, T.M., Allen, T.D., Lajtha, L.G., Schofield, R., and LORD, B.I. 1974. Stimulation of differentiation and proliferation of haemopoietic cells in vitro. J. Cell. Physiol., 82: 461473.

8. Francey, T., Jungi, T.W., Rey, O., and Peterhans, E. 1992. Culture of ovine bone marrow-derived macrophages and evidence for serum factors distinct from M-CSF contributing to their propagation in vitro. J. Leukocyte Biol., 51: 525534.

9. Frindel, E., Dumenil, D., and Sainteny, F. 1980. Role of pluripoietins in murine bone marrow stem cell differentiation. Leuk. Res., 4: 287-299.

10. Gidali, J. and LAJThA, L.G. 1972. Regulation of haemopoietic stem cell turnover in partially irradiated mice. Cell Tissue Kinet., 5: 147-157.

11. Gordon, M.Y., Riley, G.P., and Clarke, D. 1988. Heparan sulfate is necessary for adhesive interactions between human early hemopoietic progenitor cells and the extracellular matrix of the marrow microenvironment. Leukemia, 2: 804-809.

12. GREendBERGER, J.S. 1978. Sensitivity of corticosteroid-dependent insulin-resistant lipogenesis in marrow preadipocytes of obese-diabetic $(a b / a b)$ mice. Nature, 275: 752-754.

13. IHLE, J.N. and AsKew, D. 1989 . Origins and properties of hematopoietic growth factor-dependent cell lines. Int. J. Cell Cloning, 7: 68-91.

14. Ihle, J.N., Keller, J., Oroszian, S., Henderson, L.E.,
Copeland, T.D., Fitch, F., Prystowsky, M.G., Goldwasser, E., Schrader, J.W., Palaszynski, E., Dy, M., and LEBE, B. 1983. Biologic properties of homogenous interleukin 3. I. Demonstration of WEHI-3 growth factor activity, mast cell growth factor activity, $\mathrm{P}$ cell-stimulating factor activity. J. Immunol., 131: 282-287.

15. IhLE, J.N., Rein, A., and Mural, R. 1984. Immunologic and virologic mechanisms in retrovirus-induced murine leukemogenesis. In Advances in Viral Oncology (Klein, G. ed.). Vol. 4: Raven Press, New York, pp 95-137.

16. Issad, C., Croisille, L., Katz, A., Vainchenker, W., and Coulombel, L. 1993. A murine stromal cell line allows the proliferation of very primitive human $\mathrm{CD} 34+\mathrm{H} / \mathrm{CD} 38$ - progenitor cells in long-term cultures and semisolid assays. Blood, 81: 2916-2924.

17. Iтoh, K., Tezuka, H., Sakoda, H., Konno, M., Uchiyama, T., UCHINo, H., and MoRI, K.J. 1989. Reproducible establishment of hemopoietic supportive stromal cell lines from murine bone marrow. Exp. Hematol., 17: 145-153.

18. Johnson, G.R. and MetCalf, D. 1979. The commitment of multipotential hemopoietic stem cels: studies in vivo and in vitro. In Cell Lineage, Stem Cells and Cell Determination LeDouarin, N. and Monroy, A. eds, Elsevier/North-Holland Publishing Co. Amsterdam. pp. 199-213.

19. Kleinman, H.K., McGarvey, M.L., Hassell, J.R., Star, V.L., Cannon, F.B., Laurie, G.W., and Martin, G.R 1986. Basement membrane complexes with biological activity. Biochemistry, 25: 312-318.

20. Kleinman, H.K., Luckenbill-Edds, L., Cannon, F.W., and SEPHEL, G.C. 1987. Use of extracellular matrix components for cell culture. Anal. Biochem., 166: 1-13.

21. McCulloch, E.A., Siminovitch, L., Till, J.E., Russell, E.S., and BERNSTEIN, E.S. 1965. The cellular basis of genetically determined hemopoietic defect in anemic mice of genotype $\mathrm{Sl} / \mathrm{Sl}$. Blood, 26: 399-410.

22. MetCalf, D. 1986. The molecular biology and functions of the granulocyte-macrophage colony-stimulating factors. Blood, 67: $257-267$

23. Miyanomae, T., Tsurusawa, M., Fujita, J., and Mori, K.J. 1982. Role of the stromal cells in the regulation of granulopoiesis in long-term bone marrow culture: Effects of conditioned medium on granulopoiesis in vitro. Biomed., 35: 14-18.

24. Miyashita, M., Sugimoto, K., Suzuki, J., Taniguchi, S., ARAMAKI, K., and Mori, K.J. 1991. Hierarchical regulation of interleukin production: Induction of interleukin 6 (IL-6) production from bone marrow cells and marrow stromal cells by interleukin 3 (IL-3). Leuk. Res., 15: 1125-1131.

25. MORI, K.J. 1981. Patterns of proliferation and differentiation of irradiated haemopoietic stem cells cultured on normal stromal cell colonies in vitro. J. Radiat. Res., 22: 344-351.

26. MoRI, K.J. 1983. Control mechanisms of differentiation of haemopoietic stem cells. Cell Technology, 2 (in Japanese): 1375-1386.

27. MoRI, K.J. 1991. What we can say from in vitro culture work: Limitation of interpretation. Exp. Hematol., 19: 851-853.

28. Mori, K.J., Fujitake, H., Оhкubo, H., Dexter, T.M., and Iто, Y. 1979. Quantitative development of adherent cell colonies in bone marrow cell culture in vitro. Exp. Hematol., 7: 171-176.

29. Mori, K.J., Fujitake, H., Ohкubo, H., Ito, Y., and DeXter, T.M. 1978. Development of stromal cell colonies in bone marrow cell culture. Gann, 69: 689-693.

30. Mori, K.J., Izumi, H., and Seto, A. 1981. Stimulation and 
support of haemopoietic stem cells proliferation by irradiated stromal cell colonies in bone marrow cell culture in vitro. $J$. Radiat. Res., 22: 109-115.

31. Mori, K.J. and Kitamura, Y. 1976. Role of the spleen in carbon-induced radioprotection. Int. J. Radiat. Biol., 30: 487-490.

32. Ogawa, M., Porter, P.N., and Nakahata, T. 1983. Renewal and commitment to differentiation of hemopoietic stem cells (an interpretive review). Blood, 61: 823-829.

33. Онкі, K. and KонаSнI, О. 1993. Serum-mediated modification of proliferation in factor-dependent macrophage cell lines. Cell Struct. Funct., 18: 211-219.

34. Orkin R.W., Gehron, P., McGoodwin, E.B., Martin, G.R., VALENTINE, T., and SWARM, R. 1977. A murine tumor producing a matrix of basement membrane. J. Exp. Med., 145: 204220.

35. Rencricca, N.G., Rizzoli, V., Howard, D., Duffy, P., and Stohlman, F. Jr. 1970. Stem cell migration and proliferation during severe anemia. Blood, 36: 764-771.

36. Richard, L. and Swarm, R. 1963. Transplantation of a murine chondrosarcoma in mice of different inbred strains. J. Natl. Cancer Inst., 31: 953-962.

37. Roberts, R., Gallagher, J., Spooncer, E., Allen, T.D., Bloomfield, F., and Dexter, T.M. 1988. Heparan sulphate bound growth factors: a mechanism for stromal cell mediated haemopoiesis. Nature, 332: 376-378.

38. SAKODA, H. and MoRI, K.J. 1989. Distribution and differentiation of murine mast cell progenitors determined with soft agar culture. Exp. Hematol., 17: 791-794.

39. SChofield, R. 1970. A comparative study of the repopulating potential of grafts from various haemopoietic sources: CFU repopulation. Cell Tissue Kinet., 3: 119-130.

40. Shimo-OKa, T., Hasegawa, Y., and II, I. 1988. Differentiation properties of attachment of human fibroblasts to various extracellular matrix proteins. Cell Struct. Funct., 13: 515-524.

41. Shirata, K., Suzuki, T., Yanaihara, N., Sugimoto, K., and MORI, K.J. 1991. Establishment of a sarcoma cell line, MS-K, expressing Ki-ras protooncogene product from mouse bone marrow stromal cells. Biomed. Pharmacother., 45: 1-8.
42. Sugimoto, K., Fujita, J., Miyashita, M., Aramaki, K., TAMAKI, T., and MoRI, K.J. 1990. Presence of an activity indispensable for the granulocyte/macrophage colony-stimulating activity of interleukin 3 in bovine serum albumin. Leuk. Res., 14: 139-144.

43. Sugiura, K., Inaba, M., Obata, H., Yasumizu, R., InABa, K., Good, R., and IKeHARA, S. 1988. Wheat-germ agglutinin-positive cells in stem cell-enriched fraction of mouse bone marrow have potent natural suppressor activity. Proc. Natl. Acad. Sci. USA, 85: 4824-4826.

44. Suzuki, J., Taniguchi, S., Sugimoto, K., and Mori, K.J. 1992. Characterization of murine hemopoietic supportive (MS-1 and MS-5) and non-supportive (MS-K) cell lines. Leukemia, 6: 452-458.

45. Takashita, E., Sugimoto, K., Adachi, Y., and Mori, K.J. 1994. Induction of bcl-2 gene expression by intercellular information from hemopoietic supportive stromal cells to DA-1 cells. J. Cell. Physiol., 161: 367-373.

46. Till, J.E. and McCulloch, E.A. 1961. A direct measurement of the radiation sensitivity of normal mouse bone marrow cells. Radiat. Res., 14: 213-222.

47. Trentin, J.J. 1971. Determination of bone marrow stem cell differentiation by stromal hemopoietic inductive microenvironments (HIM). Amer. J. Pathol., 65: 621-628.

48. Tsuji, T., Sugimoto, K., Yanai, T., Takashita, E., and Mori, K.J. 1994. Induction of granulocyte-macrophage colony-stimulating factor (GM-CSF) and granulocyte colony-stimulating factor (G-CSF) expression in bone marrow and fractionated marrow cell populations by interleukin 3 (IL-3): IL-3-mediated positive feedback mechanisums of granulopoiesis. Growth Factors, 11: 71-79.

49. Yen, S.-E. and Stewart, C.C. 1982. Effects of serum fractions on the growth of mononuclear phagocytes. J. Cell. Physiol., 112: 107-114.

(Received for publication, November 1, 1994 and in revised form, December 31, 1994) 